were mainly excluded due to age $(n=635,58.5 \%)$ or were already current with CRC screening recommendations (154 [14.2\%] completed FIT in the previous year, and 132 [12.2\%] received a colonoscopy in the previous 10 years). FIT kits were sent to 496 of the eligible subjects; 310 (62.5\%) participants returned the kits, and $6(2.0 \%)$ received a positive FIT result. All FIT positive participants completed clinical followup with colonoscopy screening.

Discussion Firefighters in this study report that using FIT was easy or somewhat easy to perform and would prefer to use this test for screening in the future. Based on these preliminary findings, this workplace screening initiative was both feasible and acceptable in the sample of firefighters. A workplace cancer screening program has potential to increase screening rates in the firefighter population. Additional epidemiologic surveillance for annual screening follow-up is warranted.

\section{A STUDY ON THE WORKERS WITH LATENT TUBERCULOSIS INFECTION IN A TERTIARY HOSPITAL}

Gogillan Sevaratnam*. Kuala Lumpur Hospital, Federal Territory, Malaysia

\subsection{6/oemed-2018-ICOHabstracts.973}

Introduction The risk of contracting with Latent Tuberculosis Infection (LTBI) is higher among those who are dealing with patients directly. Control of LTBI is an important step towards tuberculosis elimination.

Methods LTBI was assessed by Tuberculin Skin Test by screening new workers and through contact tracing. A cross-sectional study of 362 workers infected with LTBI were detected from 2013-2016. The study was done to obtain the information on the gender, age, job category and workplace, results of chest X-ray, history of previous Bacillus Calmette-Guerin (BCG) vaccination and infection with tuberculosis. These data were collected from the Occupational Health Clinic of the hospital and a descriptive study was done.

Results 106 males (29.3\%) and 256 females (70.7\%) were evaluated. $60.2 \%$ of them were 30 years old and below. Majority were nurses $(31.8 \%)$ and $64.4 \%$ of the LTBI cases were detected from contact tracing. 261 workers $(72.1 \%)$ were from clinical departments. Majority of the workers $(76.5 \%)$ were known to be vaccinated with BCG. Only $1.6 \%$ of them had previous history of tuberculosis. As low as $12.2 \%$ of the workers had some chest x-ray changes on investigation and $17.7 \%$ were referred to pulmonologist due to various reasons. Out of 362 LTBI workers, six were found to have positive TB.

Discussion Although very few workers with LTBI became positive tuberculosis, the practices of tuberculosis infection control have to be strengthened in high risk places such as hospitals.

\section{WORK AND HEALTH: THE PERSPECTIVE OF THE ENDEMIC DISEASES COMBAT AGENTS THE MUNICIPALITY OF BELO HORIZONTE, BRAZIL}

${ }^{1} \mathrm{GC}$ Ribeiro, ${ }^{2} \mathrm{JM}$ da Silva, ${ }^{2} \mathrm{AM}$ Silveira. ${ }^{1}$ Municipal Health Department of Belo Horizonte, Belo Horizonte, Brazil; ${ }^{2}$ Universidade Federal de Minas Gerais, Belo Horizonte, Brazil

\subsection{6/oemed-2018-ICOHabstracts.974}

Introduction The purpose of this study was to understand the perception of the Endemic Diseases Combat Agents (EDCA) about their work context, mainly focusing the relationship between work and health, within the Municipal Health Department of Belo Horizonte.

Methods This is a qualitative study, under the theoretical contribution of the Work Clinics, with emphasis on Psychosociology and Clinic of Activity. The methodological procedures were bibliographic search, document analysis and focus group. The analysis of the data was based on the Bardin's Content Analysis.

Results The study showed that the professionals realise that the zoonosis service is not effectively integrated in health units. This not-belonging is one of the causes of the precarious working conditions, the feeling of invisibility and the symbolic and concrete marginalisation reported by the professionals. The Endemic Diseases Combat Agents recognise the risks to which they are exposed, highlighting the various forms of violence and lack of adequate equipment. Given the organisation of the work, they use strategies of resistance and build creative alternatives in order to defend the good work and for preservation of health at work.

Discussion An organisation reproduces a logic that prevails in society; values, expected behaviours, kinds of relationship, so it is important, the institution perceives its internal contradictions, questioning about its institutional mission and its practices. Thus, although laws and regulations define and encourage the integration of EDCA to primary care teams, this process still needs to be discussed collectively in the SMSA at all levels of management.

\section{WORKPLACE BULLYING AND ITS ASSOCIATION WITH DEPRESSION AND SELF-ESTEEM AMONG HEALTH CARE WORKERS IN SELECTED HOSPITALS IN SARAWAK}

PCM Chang, AT Su*, MM Mizanur. Universiti Malaysia Sarawak, Sarawak, Malaysia

\subsection{6/oemed-2018-ICOHabstracts.975}

Introduction Bullying at the workplace has been recognised as an increasing problem amongst healthcare staff, and has been associated with a low self-esteem and depression. Considering this view, this study was aimed to determine the proportion of bullying amongst healthcare workers in selected hospitals in Sarawak and its association between depression and selfesteem.

Methods A cross sectional study using self-administered questionnaires was done in three selected hospitals in Sarawak. The questionnaires were distributed to doctors, nurses and medical assistants during their teaching sessions. The questionnaires consisted of socio-demographics, Negative Acts Questionnaire (NAQ), Beck Depression Inventory (BDI), and Rosenberg Self-Esteem (RSE) scale. A total of 426 samples were included for analysis, after discarding 72 samples due to grossly missing information. The response rate was $71.1 \%$.

Results Majority of the respondents were of the age group 25 to 29 years old. Nurses comprised $45.5 \%$ of the study population, followed by doctors $(37.8 \%)$, whilst the rest were medical assistants and midwives. Based on the definition of bullying as at least two occurrences of any negative act either on a weekly or daily basis, $20.7 \%$ of respondents had been bullied. $22.5 \%$ of the study group had mild to severe depression, and $8.5 \%$ had a low self-esteem. There was an association between depression and being bullied, with a $p$ value of $<0.001$. Those healthcare workers who had a low selfesteem were associated with higher exposure to bullying, with 
a $\mathrm{p}$ value $<0.001$. The factors associated with bullying were the younger age group, shorter length of service, shifting work, non-managerial position and the designation as a doctor.

Conclusion A significant proportion of healthcare workers had been bullied, and bullying exposure was shown to be associated with depression and low self-esteem. Hence, regular screening for bullying, depression and low self-esteem should be done to enable early intervention.

\section{CHANGES IN TWENTY YEARS OF THE EPIDEMIOLOGICAL STATUS OF NEEDLESTICK/SHARPS INJURIES REPORTED TO JAPAN-EPINET THROUGH A NATION-WIDE SURVEILLANCE NETWORK}

1,2T Yoshikawa*, ${ }^{1} \mathrm{~K}$ Wada, ${ }^{1} \mathrm{JJ}$ Lee, ${ }^{1} \mathrm{~T}$ Mitsuda, ${ }^{1} \mathrm{H}$ Kuroshi, ${ }^{1} \mathrm{M}$ Aminaka, ${ }^{1} \mathrm{U}$ Morisawa, ${ }^{1} \mathrm{~K}$ Morikane, ${ }^{1} \mathrm{H}$ Kunishima, ${ }^{1} \mathrm{~K}$ Kidouchi, ${ }^{1} \mathrm{~K}$ Moriya. ${ }^{1}$ The Research Group for Occupational Infection Control and Prevention in Japan (JRGOICP); ${ }^{2}$ Research Centre of Overwork-Related Disorders (RECORDS), National Institute of Occupational Safety and Health (JNIOSH), Japan

\subsection{6/oemed-2018-ICOHabstracts.976}

Introduction This study aimed at examining annual logs of needlestick/sharps injuries (NSIs) collected through a voluntary nation-wide surveillance network in twenty-years for preventing occupational blood-borne infections. The emphasis was placed on revealing the past and current situations of NSIs in health care settings.

Methods Japan-EPINet format was developed by the technical support of the International Healthcare Worker Safety Centre, University of Virginia in the United States in 1996. Japan-EPINet Surveillance (JES) was conducted by the Research Group for Occupational Infection Control and Prevention in Japan (JRGOICP). Data were analysed in four phases of the nationwide surveillance network of AIDS referral hospitals out of a total of 364 registered, a total number of hospital-year was 1879. These hospitals reported employees' percutaneous injuries on a voluntary basis.

Results A total of 65,032 NSIs were reported to Japan-EPINet from 1996 to 2015. The rate of hepatitis C antibody positive cases of the total NSIs decreased from $69.9 \%(1,511 / 2,161)$ in 1996 to $11.5 \%(714 / 6,201)$ in JES2015. The proportion of NSIs due to 'recapping' decreased $(28.7 \%, 6.9 \%$ respectively). Devices caused to NSIs by winged steel needles $(25.3 \%$, $8.6 \%)$ and vacuum tube phlebotomy needles $(4.8 \%, 1.7 \%)$ were decreased, disposal syringe $(28.5 \%, 26.2 \%)$ and IV catheter $(6.7 \%, 5.2 \%)$ were fairly decreased. The proportion of Suture needle $(10.3 \%, 16.9 \%)$ and pre-filled cartridge syringe $(2.8 \%, 8.3 \%)$ were increased.

Discussion The changes of characteristics NSIs in Japan in twenty-year suggested that recognition of the risks of NSIs was vital for promoting the effective use of safety-engineered needle/sharp devices and point-of-use disposal containers because the rate of hepatitis $\mathrm{C}$ antibody positive cases among voluntary reported NSIs. The creation of the nation-wide surveillance network was effective for monitoring and evaluating NSIs and for focusing on implementation of effective countermeasures.
25 PREPARATION OF HAZARDOUS DRUGS IN BIOLOGICAL
SAFETY CABIN (BSC): THE CHALLENGE OF GETTING
HEALTHIER WORK ENVIRONMENTS

${ }^{1}$ MAmparo Benavent Benavent, ${ }^{2}$ MAmparo Ortuño Moreno. ${ }^{1}$ Hospital Clinic Universitari, Valencia, Spain; ${ }^{2}$ Hospital La Fe, Valencia, Spain

10.1136/oemed-2018-ICOHabstracts.977

Introduction Hazardous drugs are an important risk to health care workers. Some of these products may even be potentially carcinogenic.

In different Spanish hospitals it was observed that only Cytostatics drugs were prepared in biological safety cabins, leaving workers exposed to the rest of hazardous non cytostatic drugs.

Methods A bibliographical review of scientific articles and researches has been carried out, together with the laws on occupational health and recommendations of the Spanish organisms.

In the USA, research promoted the development of policies of prevention and the incorporation of these drugs in the list NIOSH.

Result After analysing the information obtained, we detected the following problems: HD's are prepared in hospitalisation rooms, where the right conditions to protect workers are nonexistent; In many cases, health care workers are given only personal protective equipment to avoid exposure; Specific health control isn't performed in most cases; National legislation obliges the risk to be taken into account for the worker. Although there are no long-term epidemiological studies, protective measures should be taken.

Discussion In many hospitals in our country HD's are not prepared in biological safety cabins. Health workers are unaware that they are exposed to these risks and no specific health training or monitoring is performed. Collaborative epidemiological researches should be promoted among Public Health Units, which have information on the prevalence rate of cancer diseases, and those responsible for occupational health prevention.

\section{HOW THE WORKING BACKS PROGRAMME HELPED STAFF MANAGE BACK PAIN, REMAIN IN WORK AND REDUCE ABSENTEEISM}

Bulfin Siobhan*, Tuohy Niamh, A Purcell, A O'Reilly. St. Vincent's University Hospital, Dublin, Ireland

\subsection{6/oemed-2018-ICOHabstracts.978}

Introduction The Working Backs Programme (WBP) is designed for staff reporting back pain as a result of work or whose work performance is affected. It's a comprehensive approach including medical assessment, provision of information and education, a designated physiotherapy and ergonomic staff referral service and a referral pathway for further investigations and/or review. The effectiveness was evaluated by an initial audit in 2012 and subsequent audits in 2015 and 2016. Methods Data was collected through questionnaires at initial consultation and post discharge for comparison. This included 